\title{
ОЦЕНКА ВОЗМОЖНОСТИ ПРИМЕНЕНИЯ СЕМЯН ЛЬНА В РЕЦЕПТУРАХ ПАШТЕТОВ ИЗ КУРИНЫХ СУБПРОДУКТОВ
}

\author{
N.A. Velichko, L.P. Sharoglazova
}

\section{THE EVALUATION OF THE POSSIBILITY OF USING FLAX SEEDS IN THE RECIPES OF PATES FROM CHICKEN BY-PRODUCTS}

Величко Надежда Александровна - д-р техн. наук, проф., зав. каф. технологии консервирования и пищевой биотехнологии Красноярского государственного аграрного университета, г. Красноярск. E-mail: vena@kgau.ru

Шароглазова Лидия Петровна - канд. техн. наук, доц. каф. технологии консервирования и пищевой биотехнологии Красноярского государственного аграрного университета, г. Красноярск. E-mail: vena@kgau.ru

Цель исследования - разработать рецептуры и принципиальную схему получения мясных паштетов с добавлением семян льна. Задачи исследования: определить дозировку добавления семян льна в паштеты из куриных субпродуктов; разработать рецептуру $u$ принципиальную схему паштета из куриных субпродуктов с добавлением семян льна; установить органолептические показатели nаштета; провести дегустационную оценку мясорастительного паштета. Приведена разработанная рецептура мясорастительного паштета с добавлением семян льна. $В$ качестве мясного сырья применяли куринье субпродукты - сердиа и желудочки. Подобрана их дозировка, обеспечивающая лучшие органолептические показатели продукта (3 \% взамен мясного фрарша). Дана органолептическая оценка опьтных образцов паштета с различным количественным содержанием семян льна в продукте. При введении семян льна 1 \% органолептические показатели мясорастительного паштета почти не изменились, появился слегка уловимый аромат семян льна. При введении семян льна 3 \% naштет приобрел яркое приятное послевкусие, структура паштета стала более привлекательной u нежной. При введении семян льна 5 \% ощуща-
Velichko Nadezhda Alexandrovna - Dr. Techn. Sci., Prof., Head, Chair of Technology of Canning and Food Biotechnology, Krasnoyarsk State Agrarian University, Krasnoyarsk.

E-mail: vena@kgau.ru

Sharoglazova Lidiya Petrovna - Cand. Techn. Sci., Assoc. Prof., Chair of Technology of Canning and Food Biotechnology, Krasnoyarsk State Agrarian University, Krasnoyarsk.

E-mail: vena@kgau.ru

ется горьковатьй привкус семян льна, консистенция паштета становится суховатой. При введении семян льна 10 \% консистенция naштета становится сухой, присутствует горьковатый привкус. Приведены результаты дегустационной оценки мясорастительных nаштетов, которые показали наивысшую оценку (4,88 балла) при добавлении 3 \% семян льна в naumeтную массу. Полученные результаты по разработанной рещептуре мясорастительных паштетов по органолептическим показателям соответствуют ГОСТ $P$ 9959-2015 и TP TC 034/2013. Предложена принципиальная схема получения мясорастительного паштета, включающая добавление семян льна.

Ключевые слова: naштет, рецептура, семена льна, дозировка, органолептические показатели, дегустационная оценка, куриные субпродукты.

The research objective was to develop the recipe and schematic diagram of receiving meat pates with addition of flax seeds. The research problems were to define the dosage of addition of flax seeds in pates from chicken by-products; to develop the recipe and schematic diagram of the pate from the chicken by-products with addition of flax seeds; to 
establish organoleptic indicators of pate; to carry out tasting assessment of meat and cereal pate. Developed recipe of meat and cereal pate with addition of flax seeds was given. As meat raw materials applied chicken by-products - hearts and ventricles. Their dosage providing the best organoleptic indicators of a product was picked up (3\% instead of mincemeat). Organoleptic assessment of the prototypes of the pate with various quantitative content of flax seeds in the product was given. At introduction of flax seeds of $1 \%$ organoleptic indicators of meat and cereal pate almost did not change, there was slightly audible aroma of flax seeds. At introduction of $3 \%$ of flax seeds the pate got bright pleasant aftertaste, the structure of the pate became more attractive and gentle. At $5 \%$ introduction of flax seeds bitterish smack of flax seeds was felt, the consistence of the pate became dryish. At $10 \%$ introduction of flax seeds the consistence of the pate became dry, there was a bitterish smack. The results of tasting assessment of meat and cereal pates which showed the highest assessment (4.88 points) at addition of $3 \%$ of seeds of flax in the pate weight were given. Received results on developed compounding of meat and cereal pates on organoleptic indicators correspond to State Standard P 9959-2015 and TR TC 034/2013. Schematic diagram of receiving meat and cereal paste including flax seeds was offered.

Keywords: pate, recipe, flax seeds, dosage, organoleptic indicators, tasting assessment, chicken by-products.

Введение. Обеспечение населения низкокалорийным, легкоусвояемым продуктом, содержащим оптимальное количество полиненасыщенных жирных кислот и незаменимых аминокислот, может быть достигнуто при комбинировании растительного и мясного сырья. Разработка новых рецептур и создание оригинальных технологий изготовления мясорастительных продуктов питания с оптимальным содержанием белков, жиров, витаминов, макро-, микроэлементов и других физиологически значимых компонентов - одна из важных целей пищевой индустрии.

Льняное семя в настоящее время пользуется большой популярностью в качестве пищевой добавки. Хлебобулочные продукты с добавкой льняного семени приобретают как нежный вкус вследствие большого количества жира, так и привлекательную на вид корочку [1].

Исследования показали, что потребление хлеба, обогащенного льняными семенами, в течение четырех недель способствует снижению содержания холестерина. Доказана возможность использования льняной муки для приготовления диетических экструдированных концентратов типа «сухие завтраки» [2].

Семена льна применяются в рецептурах функциональных продуктов [3]. В 100 г семян льна содержится 41 г жира, в составе которого в основном присутствуют полиненасыщенные жирные кислоты. По сравнению с другими растительными маслами льняное масло имеет наиболее низкое содержание нежелательных для рациона человека насыщенных жирных кислот. 100 г семян льна обеспечивают более $20 \%$ суточной потребности человека в энергии, 30 \% - в белках, более 50 \% - в жирах, фросфоpe [4]. Установлено высокое содержание в семенах льна водо- и жирорастворимых витаминов, макро- и микроэлементов, таких как кальций, магний, калий, железо, марганец, селен. Энергетическая ценность семени льна составляет 534 кКал на 100 г.

Исходя из химического состава семян льна, представляло интерес исследование возможности их применения в рецептурах мясных паштеTOB.

На данный момент доля паштетов в ассортименте мясной консервации незначительна. Паштеты относятся именно к тем мясопродуктам, технология изготовления которых позволяет рационально использовать сырье, а также сочетать в себе различные виды. Помимо мясных компонентов в их состав можно вводить растительное сырье, другие пищевые компоненты [5].

Цель исследования: разработка рецептуры и принципиальной схемы получения мясных паштетов с добавлением семян льна.

Задачи исследования:

- определить дозировку добавления семян льна в паштеты из куриных субпродуктов;

- разработать рецептуру и принципиальную схему паштета из куриных субпродуктов с добавлением семян льна;

- установить органолептические показатели паштета; 
- провести дегустационную оценку мясорастительного паштета.

Методы и материалы исследования. Для получения паштетов применяли следующие виды сырья и материалы:

- сердца куриные - по ГОСТ 32244-2013;

- желудочки куриные - по ГОСТ Р 555002013;

- жир куриный - по ГОСТ Р 54676-2011;

- лук репчатый свежий - по ГОСТ 517832001;

- морковь свежая - по ГОСТ 32284-2013;

- мускатный орех - ГОСТ 29048-9;

- перец черный молотый - по ГОСТ 29050-91;
- соль поваренная пищевая - по ГОСТ Р 51 574-2000;

- вода питьевая - по ГОСТ Р 51232-98.

Сырье, применяемое для приготовления паштетов, соответствовало требованиям технической документации и ТP ТС 034/2013 «О безопасности мяса и мясной продукции».

Органолептическую оценку паштетов проводили согласно ГОСТ9959-2015 «Продукты мясные. Общие условия проведения органолептической оценки» [6].

Результаты исследования и их обсуждение. В таблице 1 приведена рецептура контрольного образца паштета из куриных субпродуктов - сердец и желудочков.

Таблица 1

Рецептура паштета из куриных субпродуктов на 100 кг продукции (контрольный образец)

\begin{tabular}{|l|c|}
\hline \multicolumn{1}{|c|}{ Компонент } & Количество, кг \\
& \\
\hline Куриные сердца & 31,7 \\
\hline Куриные желудочки & 34,5 \\
\hline Жир куриный & 5 \\
\hline Бульон & 11,2 \\
\hline Лук & 10,2 \\
\hline Морковь & 4,8 \\
\hline Перец & 0,8 \\
\hline Соль & 1,0 \\
\hline Мускатный орех & 0,8 \\
\hline
\end{tabular}

В рецептуры опытных образцов вносили предварительно измельченные семена льна в различной дозировке $(1 ; 3 ; 5 ; 10 \%)$ взамен мясных субпродуктов, все остальные ингредиенты использованы как в рецептуре контрольного образца (см. табл. 1). В качестве мясного сырья применяли куриные субпродукты - сердца и желудочки.

Рациональной дозой с точки зрения технологии можно считать такое количество растительной добавки, которое не ухудшит вкус и цвет паштетных изделий. Подготовку компонентов рецептуры (желудочков, сердец, лука, моркови и др.) проводили согласно принципиальной схе- ме, приведенной на рисунке. Приготовление паштетов осуществляли в куттере в следующей последовательности: 1) загрузка и измельчение в течение 2-3 мин предварительно сваренных куриных желудочек и сердец, соли, 1/3 от общего количества бульона $\left(\mathrm{t}=0-4{ }^{\circ} \mathrm{C}\right) ; 2$ ) добавление бланшированной моркови лука, 2/3 бульона порциями и куттерование 2-3 мин; 3) введение в куттер куриного жира до равномерного распределения в объеме фарша. Семена льна вводили на этапе куттерования мясного фарша. Общая продолжительность приготовления - 6-8 мин.

В таблице 2 приведены различные дозировки внесения семян льна в паштетную массу. 


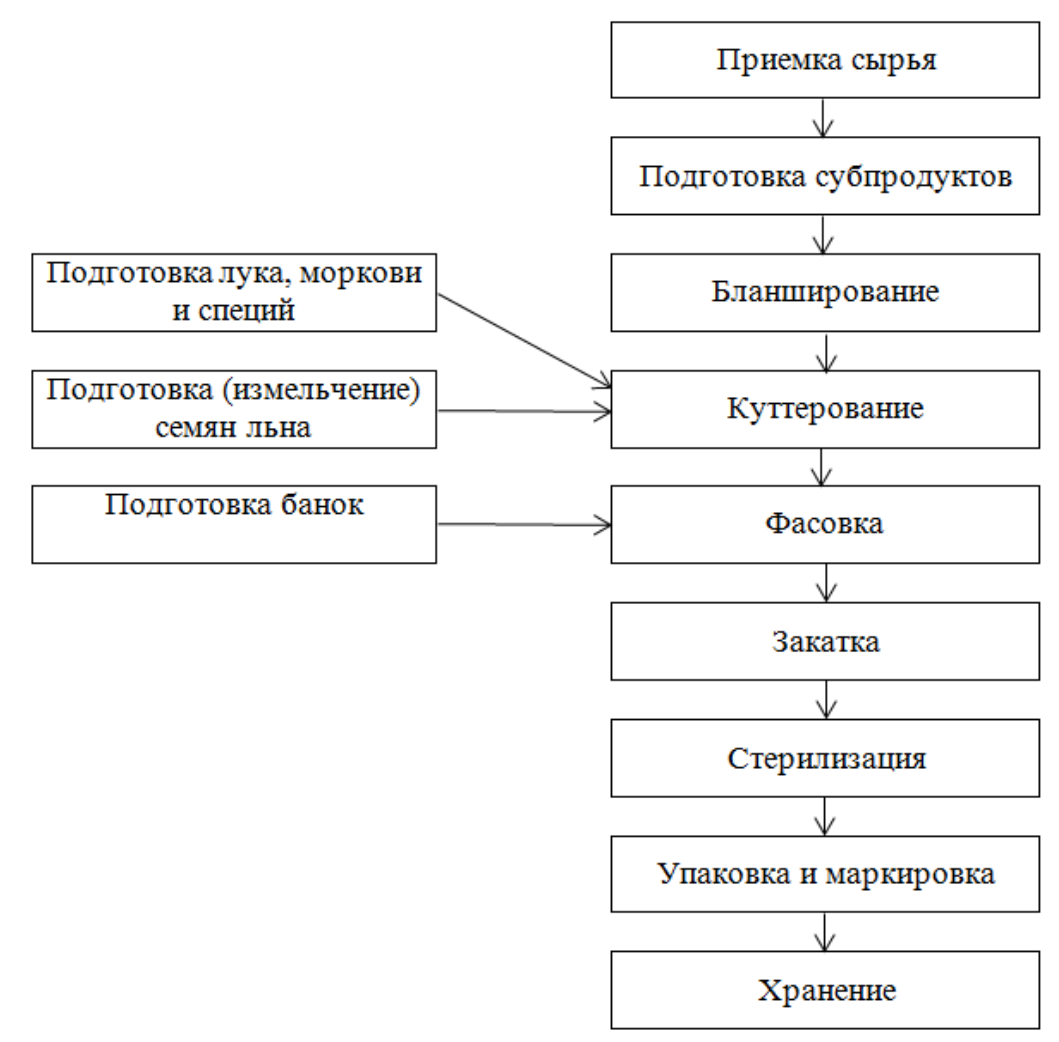

Принципиальная схема получения мясорастительного паштета

Таблица 2

Дозировки внесения семян льна

\begin{tabular}{|l|c|c|c|c|c|}
\hline \multirow{2}{*}{\multicolumn{1}{|c|}{ Показатель, г }} & \multicolumn{5}{|c|}{ Образец } \\
\cline { 2 - 6 } & Контрольный & 1 & 3 & 5 & 10 \\
\cline { 3 - 6 } & 168 & 167 & 165 & 163 & 158 \\
\hline $\begin{array}{l}\text { Основное и вспомога- } \\
\text { тельное сырье }\end{array}$ & 0 & 1 & 3 & 5 & 10 \\
\hline Семена льна & 168 & 168 & 168 & 168 & 168 \\
\hline $\begin{array}{l}\text { Масса готовой } \\
\text { продукции }\end{array}$ & & & & & \\
\hline
\end{tabular}

При введении семян льна $1 \%$ органолептические показатели паштета почти не изменились, появился слегка уловимый аромат семян льна. При введении семян льна 3 \% паштет приобрел яркое приятное послевкусие, структура паштета стала более привлекательной и нежной. При введении семян льна $5 \%$ ощущается горьковатый привкус семян льна, консистенция паштета становится суховатой. При введении семян льна 10 \% консистенция паштета становиться сухой, присутствует горьковатый привкус. Поскольку задачей является не только повышение пищевой и биологической ценности продукта, но и улучшение его вкусовых качеств, то по органолептическим показателям дозировкой, обеспечивающей лучшие показатели качества, является добавление семян льна в количестве $3 \%$ взамен мясного сырья.

Органолептические показатели паштета из куриных субпродуктов с добавлением семян льна (3 \%) приведены в таблице 3. 
Органолептические показатели паштета из куриных субпродуктов с добавлением семян льна (3\%)

\begin{tabular}{|l|l|}
\hline \multicolumn{1}{|c|}{ Показатель } & \multicolumn{1}{c|}{ Характеристика } \\
\hline Внешний вид & $\begin{array}{l}\text { Однородная мелкоизмельченная масса с незначитель- } \\
\text { ным количеством выплавленного жира }\end{array}$ \\
\hline Цвет & От розовато серого до коричневато-серого \\
\hline Запах, вкус & $\begin{array}{l}\text { Свойственный мясному паштету с ароматом пряностей } \\
\text { и приятным послевкусием семян льна }\end{array}$ \\
\hline Консистенция & Пастообразная, однородная по всей массе \\
\hline Массовая доля поваренной соли, \% & \multicolumn{1}{|c|}{$1,0-1,3$} \\
\hline
\end{tabular}

Экспериментальными исследованиями доказано, что увеличение дозировки внесения семян льна от 3 до 4 \% приводит к улучшению технологических свойств паштета, его консистенции и вкуса, но количество семян льна в паштете бо- лее 5 \% ухудшает органолептические показатели продукта.

Дегустационная оценка опытных образцов проводилась по пятибалльной шкале (табл. 4).

\section{Дегустационная оценка образцов паштета}

\begin{tabular}{|l|c|c|c|c|c|c|c|}
\hline \multicolumn{1}{|c|}{ Образец } & $\begin{array}{c}\text { Внешний } \\
\text { вид }\end{array}$ & Цвет & Запах & $\begin{array}{c}\text { Конси- } \\
\text { стенция }\end{array}$ & Вкус & Сочность & $\begin{array}{c}\text { Средняя } \\
\text { оценка }\end{array}$ \\
\hline Контрольный & 4,5 & 4,8 & 4,0 & 4,5 & 4,5 & 4,7 & 4,5 \\
\hline $\begin{array}{l}1 \% \text { семян } \\
\text { льна }\end{array}$ & 4,5 & 4,8 & 4,2 & 4,3 & 4,6 & 4,7 & 4,5 \\
\hline $\begin{array}{l}3 \% \text { семян } \\
\text { льна }\end{array}$ & 5 & 5 & 4,5 & 4,9 & 5 & 4,9 & 4,88 \\
\hline $\begin{array}{l}5 \% \text { семян } \\
\text { льна }\end{array}$ & 4,0 & 4,0 & 4,0 & 4,0 & 4,0 & 4,2 & 4,03 \\
\hline $\begin{array}{l}10 \% \text { семян } \\
\text { льна }\end{array}$ & 3,9 & 3,9 & 3,5 & 3,9 & 3,9 & 3,1 & 3,7 \\
\hline
\end{tabular}

Как следует из приведенных данных таблицы 4, наибольший показатель - 4,88 балла наблюдался при 3 \% добавлении семян льна в паштет из куриных субпродуктов.

Выводы. Разработана рецептура мясорастительного паштета из куриных субпродуктов с добавлением семян льна. Подобрана дозировка введения семян льна (3 \%) взамен мясного фарша, обеспечивающая наилучшие органолептические показатели паштета. Проведена дегустационная оценка потребительских свойств паштета, которая показала лучший результат (4,88 балла) при добавлении 3 \% семян льна в паштетную массу. Полученные результаты по разработанной рецептуре паштетов из мяса кролика с добавлением в качестве ингре- диента семян льна по органолептическим показателям соответствуют ГОСТ Р 9959-2015 и ТР TC 034/2013 [7].

Предложена принципиальная схема получения мясорастительного паштета из куриных субпродуктов с добавлением семян льна.

\section{Литература}

1. Пащенко Л.П., Странадо Г.Г., Булгакова Н.Н. Использование семян льна для повышения биологической ценности хлебобулочных изделий // Хранение и переработка сельхозсырья. - 2003. - № 4.

2. Урубков С.А., Королёв А.А.,. Коптяева И.С., Корнева Л.Я. Разработка диетических экс- 
трудированных поликомпонентных продуктов со льном // Ползуновский вестник. 2018. - № 4. - С. 84-88.

3. Миневич И.Э. Разработка технологических решений переработки семян льна для создания фуункциональных пищевых продуктов: дис. ... канд. техн. наук. - М., 2009. $176 \mathrm{C}$.

4. Полякова Е.Д., Заикина М.А. Витаминный и минеральный состав льна пищевого, реализуемого на потребительском рынке г. Курска // Технология и товароведение инновационных пищевых продуктов. - 2013. № 1. - C. 19-24.

5. Величко Н.А., Шароглазова Л.П., Аешина Е.Н. Разработка рецептуры и технологии мясорастительного паштета // Вестник КрасГАУ. 2019. - № 10. - C. 147-152.

6. ГОСТ 9959-2015. Продукты мясные. Общие условия органолептической оценки Введ. 1993-01-01. - М.: Стандартинформ, 2010. - 12 c.

7. TP ТС 034/2013. О безопасности мяса и мясной продукции (утв. решением Комиссии Таможенного союза от 9 октября 2013 г. № 68). - М., 2013.

\section{Literatura}

1. Pashchenko L.P., Stranado G.G., Bulgakova N.N. Ispol'zovanie semyan I'na dlya povysheniya biologicheskoj cennosti hlebobulochnyh izdelij // Hranenie i pererabotka sel'hozsyr'ya. - 2003. - № 4.

2. Urubkov S.A., Korolyov A.A.,. Koptyaeva I.S., Korneva L.Ya. Razrabotka dieticheskih ekstrudirovannyh polikomponentnyh produktov so I'nom // Polzunovskij vestnik. - 2018. № 4. - S. 84-88.

3. Minevich I.E. Razrabotka tekhnologicheskih reshenij pererabotki semyan I'na dlya sozdaniya funkcional'nyh pishchevyh produktov: dis. ... kand. tekhn. nauk. - M., 2009. - $176 \mathrm{~s}$.

4. Polyakova E.D., Zaikina M.A. Vitaminnyj i mineral'nyj sostav I'na pishchevogo, realizuemogo na potrebitel'skom rynke g. Kurska // Tekhnologiya i tovarovedenie innovacionnyh pishchevyh produktov. - 2013. - № 1. - S. 19-24.

5. Velichko N.A., SHaroglazova L.P., Aeshina E.N. Razrabotka receptury i tekhnologii myasorastitel'nogo pashteta // Vestnik KrasGAU. - 2019. - № 10. - S. 147-152.

6. GOST 9959-2015. Produkty myasnye. Obshchie usloviya organolepticheskoj ocenki Vved. 1993-01-01. - M.: Standartinform, 2010. - $12 \mathrm{~s}$.

7. TR TS 034/2013. O bezopasnosti myasa $\mathrm{i}$ myasnoj produkcii (utv. resheniem Komissii Tamozhennogo soyuza ot 9 oktyabrya $2013 \mathrm{~g}$. № 68). - M., 2013. 